\title{
Representações sociais de educação em saúde em tempos de AIDS
}

\author{
Social representations of health education in a time of AIDS \\ Representaciones sociales de educación para la salud en la era del SIDA
}

\author{
Elizabeth Teixeira', Denize Cristina de Oliveira" \\ ' Universidade do Estado do Pará, Escola de Enfermagem Magalhães Barata, \\ Departamento de Enfermagem Comunitária. Belém-PA, Brasil. \\ "Universidade do Estado do Rio de Janeiro, Faculdade de Enfermagem, \\ Departamento de Fundamentos de Enfermagem. Rio de Janeiro-RJ, Brasil.
}

\section{Submissão: 04-06-2014 Aprovação: 16-07-2014}

\section{RESUMO}

Estudo qualitativo e descritivo, cujo objetivo foi identificar e analisar as representações sociais de educação em saúde à pessoa vivendo com HIV entre profissionais de saúde. Os cenários foram três serviços de atenção à DST/HIV/AIDS, em Belém-PA, Brasil, e 37 profissionais de saúde participaram da pesquisa. A coleta de dados deu-se em 2012-2013 por meio de entrevista em profundidade; a análise utilizou o software Alceste 4.10. Com base no conjunto dos resultados foi possível vislumbrar que a educação em saúde pode ser compreendida a partir de categorias: a configuração do agir educativo; as condições sine qua non: educação no trabalho e estrutura da unidade; o processo pedagógico. Conclui-se que as representações sociais configuram-se como orientação-informação para precaução-prevenção e revelam-se no movimento do agir persistente ao emergente, o que suscita uma educação em saúde permanente para se chegar à integralidade nos serviços.

Descritores: Educação em Saúde; HIV; AIDS; Profissional de Saúde.

\begin{abstract}
This is a qualitative and descriptive study, which aimed at identifying and analyzing social representations of health education to HIV patients among health professionals. The setting included three healthcare DST/HIV/AIDS services in Belém-PA, Brazil, and 37 health professionals participated in the study. Data collection was conducted in 2012-2013 on the basis of in-depth interviews and analysis was made on Alceste 4.0 software. Final results indicated that health education can be comprehended in light of categories: educational action; sine qua non: education and training at work, and unit structure; teaching-learning process. Conclusions show that social representations are set as guidance-information for precaution-prevention and that they come forth along continuous and emerging action flow, bringing about permanent health education to ensure healthcare services in full.
\end{abstract}

Key words: Health Education; HIV; AIDS; Health Professional.

\section{RESUMEN}

Estudio cualitativo y descriptivo, que objetivó identificar y analizar las representaciones sociales de educación en salud a la persona viviendo con HIV entre profesionales de salud. Los escenarios fueron tres servicios de atendimiento al DST/HIV/ SIDA, en Belém-PA, Brasil, y 37 profesionales de salud participaran del estudio. La colecta de datos se dio en 2012-2013, por medio de entrevista en profundidad y el análisis utilizo el software Alceste 4.10. Con base en el conjunto de los resultados fue posible vislumbrar que la educación en salud puede ser comprendida a partir de categorías: la configuración del acto educativo; las condiciones sine qua non: educación en el trabajo y estructura de la unidad; el proceso pedagógico. Se concluye que las representaciones sociales se configuran como orientación-información para precaución-prevención y se revelan en el movimiento del acto persistente al emergente, lo que suscita una educación en salud permanente para Ilegarse a la integralidad en los servicios.

Palabras clave: Educación en Salud; HIV; SIDA; Profesional de Salud.

\section{AUTOR CORRESPONDENTE Elizabeth Teixeira E-mail: etfelipe@hotmail.com}




\section{INTRODUÇÃO}

As mudanças do saber reificado configuram a dinâmica da síndrome da imunodeficiência adquirida (Aids) e do vírus da imunodeficiência humana (HIV), com impacto nas unidades de atendimento e no agir da equipe de saúde. No que se referem às mudanças representacionais, estas são observadas tanto em relação à epidemia e ao vírus, como sobre os modos de cuidar e educar em saúde nesse âmbito, confirmando-se uma transição de sentidos (negativos para positivos), de discursos (da imobilização "não há o que fazer" para a mobilização "já há o que fazer"), e também a ocorrência de permanentes e emergentes construções simbólicas e metafóricas associadas ao contexto epidemiológico e sócio profissional ${ }^{(1)}$.

No que tange às práticas educativas relacionadas ao processo saúde-doença em geral, estas têm sido pautadas por perspectivas pendulares: ora a partir de um eixo vertical-individual, ora por um horizontal-coletivo. Abordagens "verticalizadas" dão ênfase à eleição informada sobre riscos, mudanças de hábitos e comportamentos, persuasão clínica e prescrição de práticas, intervenção individual, responsabilização do sujeito com adaptação às condutas, uma educação em saúde baseada em informação. Abordagens "horizontalizadas" valorizam o aumento das capacidades pessoais e a emancipação, a transformação da realidade, a intervenção coletiva, problematizadora e dialógica, uma educação em saúde baseada em formação, necessidades, expectativas, saberes e valores ${ }^{(2)}$. As primeiras, associadas ao paradigma dominante hegemônico, atendem aos interesses do Estado, com predomínio até os anos 70; as segundas relacionam-se às mudanças paradigmáticas na saúde a partir dos anos 80, e vão ao encontro dos princípios do SUS, incorporando um arcabouço teórico Freireano. O que se constata, no entanto é que tais abordagens, apesar de introduzidas nos novos discursos, não vem se traduzindo com a intensidade desejada no mundo das práticas ${ }^{(3)}$.

No que tange a práticas educativas no contexto HIVAids, que emergem concomitantes às mudanças na saúde nos anos 80, constata-se que, de imediato, no início da epidemia, são pautadas pela abordagem "verticalizada" e se consubstanciam numa educação pelo medo, veiculada pela comunicação de massa, dirigida à grupos de risco, num enfoque campanhista-panfletário ${ }^{(4)}$. Tais práticas são associadas à lógica disciplinadora, aos pressupostos cognitivo-comportamentais-tradicionais, valorizando a prevenção da doença, em que aspectos biológicos dão o "tom" aos discursos(5).

Os avanços da Política Nacional de DST\Aids foram reconfigurando o perfil das equipes de saúde, com a introdução do "aconselhamento educativo" em especial, que suscita o redirecionamento do modelo indivíduo-centrado para o coletivo-centrado, apontando para a decisão informada e a adesão. Observa-se explicitamente uma tendência crítico-progressista, valorizando a promoção da saúde, em que aspectos subjetivos ganham destaque ${ }^{(4)}$. Da abordagem "verticalizada" centrada no risco (com foco nos deveres), as premissas da Política Nacional de DST \Aids saltam para a transversalidade centrada na vulnerabilidade (com foco nos direitos) ${ }^{(5)}$. Há, no entanto, que se refletir sobre a incorporação de tais premissas no mundo das unidades de atendimento às pessoas vivendo com HIV.

Parte-se do pressuposto que a educação em saúde, aqui compreendida como agir educativo, no cotidiano do cuidado em HIVAids, pode se desdobrar em diferentes tipologias e modelos, e anunciar (ou não) as transformações e transições apontadas. Assim, as Representações Sociais (RS) de educação em saúde à pessoa vivendo com HIVAids, elaboradas pela equipe de saúde, podem revelar nuanças e interfaces de construções sociocognitivas distintas, o que nos interessa analisar e discutir.

Acessar as RS dos profissionais de saúde em contextos de atendimento à pessoa vivendo com HIVAids implica em compreender como interpretam e que sentidos atribuem a este objeto. As RS dão sentido, guiam e conduzem os grupos sociais. Nos diferentes contextos de atuação profissional, se forjam enquanto saberes práticos, e os sujeitos sociais aí inseridos configuram-na a partir das experiências vivenciadas nas unidades, contexto histórico, cultural e espacial ${ }^{(1)}$.

Este estudo tem por objetivo identificar e analisar as representações sociais de educação em saúde à pessoa vivendo com HIV entre profissionais de saúde. Acredita-se que tais representações poderão suscitar reflexões e apontar as (im)possibilidades do agir educativo com pessoas vivendo com HIV Aids, o que poderá favorecer intervenções concretas nestes contextos, com vistas a contribuir com a qualidade da prática educativa.

Este trabalho consiste em um recorte temático do Projeto Multicêntrico "As transformações do cuidado de saúde e de enfermagem em tempos de Aids: representações sociais e memórias de enfermeiros e profissionais de saúde".

\section{MÉTODO}

Trata-se de um estudo de caráter qualitativo e descritivo, cujo referencial teórico-metodológico foi a Teoria das Representações Sociais (TRS), com base na perspectiva processual, que enfatiza o processo de constituição das representações sociais, atribuindo importância ao seu produto, os conteúdos. As representações sociais são formas de conhecimento socialmente produzidas e partilhadas, com uma orientação prática, concorrendo para a construção de uma realidade comum a determinado conjunto social(6), perspectiva esta que justifica a opção pela TRS.

O cenário do estudo consistiu em três serviços de atenção às pessoas vivendo com HIVAids, situados no município de Belém, Pará, Brasil. Participaram da pesquisa 37 profissionais de saúde. A amostra foi por conveniência; os profissionais foram escolhidos por terem participado da primeira etapa do projeto multicêntrico e estarem no momento das entrevistas atuando nos serviços.

Foram incluídos aqueles que atendem cotidianamente pessoas vivendo com HIVAids nas respectivas unidades. Os sujeitos, em sua maioria, são do sexo feminino, idade de 31 a 40 anos, com tempo de formação de 6 a 15 anos e tempo de atuação com pessoas vivendo com HIVlAids menor ou igual a 5 anos. Quanto à área de formação são: 10 técnicos de enfermagem, 6 enfermeiras, 6 assistentes sociais, 6 médicos, 
2 psicólogos, 2 nutricionistas, 2 farmacêuticos, 2 terapeutas ocupacionais e 1 fisioterapeuta.

Os dados foram coletados entre setembro de 2012 e junho de 2013 por meio de entrevista em profundidade guiada por um roteiro com cinco blocos temáticos. O roteiro foi testado e validado no decorrer da fase piloto do estudo. Para este manuscrito o corpus foi constituído das respostas obtidas aos cinco blocos temáticos, que foi submetido a análise lexical, e para tal, utilizou-se o software Alceste 4.10. Realizou-se a padronização de alguns termos considerados importantes para a análise, e obteve-se um total de 211 páginas e 932.217 caracteres. Separando cada uma das entrevistas, inseriu-se uma linha estrelada, com 7 variáveis: número do sujeito, unidade, idade, gênero, tempo de formação, função atual, tempo de atuação com pessoas com HIVAids.

Foram utilizados os seguintes recursos do Alceste: análise standard do conjunto do corpus; análise de redes associativas da palavra-expressão educação_saúde e análise cruzada (Tri-Croisé) para a mesma palavra-expressão.

Foram seguidas as normas em vigor na época, com base na Resolução 196/96. Obtivemos parecer favorável do Comitê de Ética da UERJ: nº. 074/2010-COEP; da CONEP - Registro 16755, Parecer no 053/2012; do Comitê de ética da UEPA (CAAE, protocolo 0069.0.321.000-10). O aceite foi obtido após assinatura do TCLE, em que os profissionais de forma voluntária se manifestaram favoráveis à participação. A todos foi garantido sigilo e anonimato.

\section{RESULTADOS}

Na Análise Standard, foram identificadas 37 Unidades de Contexto Iniciais $(\mathrm{UCl})$, relativas às entrevistas. O corpus foi dividido em 3.959 Unidades de Contexto Elementares (UCE), o número de classes foi 5 e o número mínimo de UCE por classe foi 198.

O corpus de análise no seu todo contém elementos que abordam o tema "cotidiano e contexto do cuidado em tempos de Aids". Inicialmente esse corpus sofreu uma primeira partição em dois subgrupos, originando, de um lado, um subcorpus nomeado "contexto do HIVAids: passado e presente", constituído pelas classes 2 e 3 . Do outro lado gerou um segundo subcorpus, nomeado "cotidiano do cuidado: práticas e sujeitos", com uma classe específica, a classe 5, nomeada "práticas de autocuidado da equipe" e pelas classes 1 e 4, mais comuns entre si, nomeadas "cotidiano do cuidado", que foram geradas numa segunda partição.

A classe 1 apontou para a dinâmica do cuidado no serviço e os processos educativos. A classe 4 apontou para a equipe que cuida, sua composição e interação. Este resultado permitiu compreender que a classe 1 , que será considerada com mais ênfase neste texto, engloba os léxicos que exploram o objeto recortado para esta análise.

A classe 1 representa $33 \%$ do corpus analisado e contem 888 UCE. As variáveis de maior associação à essa classe foram: categoria equipe multiprofissional geral, idade entre 41 e 50 anos, atuação no CTAISAE de 6 a 15 anos de tempo de atendimento com pessoas vivendo com para HIV. Com base na Classificação Ascendente Hierárquica $(\mathrm{CAH})$, e o dendograma que daí emergiu para a classe, foi possível identificar duas dimensões para os processos educativos: "educação no trabalho" e "educação em saúde". Neste artigo, serão discutidas as especificidades e associações da dimensão "educação em saúde", englobando no seu bojo a educação no trabalho.

Com o recurso Redes Associativas, obteve-se uma figura com dezoito Formas Reduzidas (FR). Na Análise Cruzada (Tri-Croisé) foi gerada uma primeira classe específica com 207 UCE, representativas da parte do corpus mais associada à educação em saúde, formada por meio de 10 entrevistas; a segunda classe gerada com o restante do corpus não foi alvo de análise. As FR que revelaram maiores valores no teste de Qui-quadrado, e assim maior associação estatística com a palavra-expressão educação em saúde, em ordem decrescente foram: orient, orientações, palestra, campanha, dar_informação, trabalho_gru, tarefa, escol, precauc, papel, distribui, preservativo, adesão. As variáveis de maior associação à essa classe específica foram as mesmas da classe 1.

$\mathrm{Na}$ análise textual do conjunto de dados obtidos com os três recursos do software, ressaltamos as conexões e ligações reveladas na constelação semântica dos dados associativos e discursivos, os "topoi" ou ligações comuns sobre os quais o mundo dos discursos dos profissionais sobre educação em saúde se constroem ${ }^{(12)}$. Com base no conjunto dos resultados foi possível vislumbrar que a educação em saúde pode ser compreendida a partir de 4 categorias, que são apresentadas a seguir.

\section{A configuração do agir educativo}

Os profissionais de saúde concebem a educação em saúde como ato-tarefa de orientação-informação, que se difere do tratamento, e é mais associada ao cuidado. Para os profissionais de enfermagem a educação em saúde é do âmbito do cuidado de enfermagem. As UCE a seguir expressam esse significado.

Há diferenças entre tratamento e cuidado, o tratamento é a medicação e a consulta enfermagem; já as práticas de cuidado enfermagem são as orientações da pessoa vivendo com HIV, a educação saúde. (E 0275-Enfermeira)

A prática de cuidado_saúde é a precaução, quando ensina o uso do preservativo, quando vai dar uma palestra, educação saúde. E o tratamento já é quando está na assistência, que recebe antirretrovirais, orientação psicológica, nutricional, fonoaudióloga. (E287-Assistente Social)

Sobre o cotidiano da unidade, identificamos expressões, contidas em diferentes UCE, que dão concretude à dialética do agir educativo em diferentes tempos-movimentos considerados importantes e da responsabilidade de toda a equipe: "tento fazer, fazemos, a equipe continua fazendo"; "deveria ter, tem que ter, temos que estar orientando sempre, nós tínhamos que orientar mais"; "acho muito importante, é nosso papel, é tarefa de todos nós".

Uma das finalidades da orientação-informação referida 
pelos profissionais é a precaução-prevenção (auto e a heteroprecaução), que envolve as pessoas vivendo com HIVAids e sua rede de contatos. Outra finalidade destacada é a proteção, que se amplia para o âmbito da família.

Quanto à precaução dos próprios pacientes HIV_positivo, só orientação, educação_saúde. Nós tentamos orientar: você não pode fazer isso, você não pode se aplicar em casa, se você se aplicou seringa, você tem que jogar numa caixa fechada, não pode jogar em lixo comum. ( $E$ 0276-Técnico de Enfermagem)

Um exemplo: o uso de luvas; se a pessoa HIV_positivo se ferir, evitar o contato social, e a família não pega; isso para não descriminar, não separar talheres, isso nós orientamos. (E 0287-Assistente Social)

Aí nós orientamos: olha, nós estamos usando máscara para Ihe proteger, porque estou muito resfriada. É nesse sentido. Em todos os aspectos, ele tem que proteger a pessoa que está com ele; tem que fazer uso do preservativo, tem que proteger quem está no trabalho dele. (E 0261-Enfermeira)

Os profissionais em seus discursos utilizam com frequência a expressão "você", que pode indicar (ou não) "Eu faço"; de tal posicionamento pode-se inferir de que lugares concebem, executam elou guiam o agir educativo:

Quando há um resultado positivo em que a pessoa ficou muito abalada, ai você tenta acolher, orientar, educação_ saúde. (E 0286-Assistente Social)

Continua sendo uma demanda não suprida atualmente e acabamos fazendo formiguinha no consultório, mas se você conseguir ter um trabalho_grupo, educação_saúde consistente, você atende o que é comum à maioria, e as especificidades você traz para o consultório. (E 0273-Psicólogo)

Num movimento temporal (passado, presente, futuro), os profissionais configuram um conceito de educação e uma finalidade; o ato-tarefa se concretiza na unidade (presença) ou não (ausência), é executado por quem fala (eu, nós) ou pelos outros (equipe, serviço), e envolve tanto a pessoa vivendo com HIVAids como sua rede de contatos. Constatamos que para a presença do agir educativo, há que se ter certas condições, apontadas na próxima categoria.

Os profissionais declaram que o agir educativo atinge outros sujeitos da sua rede de relações, como familiares e amigos. A precaução-prevenção é também incorporada no viver do profissional fora do âmbito do serviço.

A minha atuação tem repercussões, eu sempre procuro estar orientando as pessoas, pois alguns familiares e amigos sempre vêm me procurar, tirar alguma dúvida e até mesmo me convidar para participar de alguma palestra de algum assunto em lugares que não seja o meu local de trabalho. (E 0217-Terapeuta Ocupacional)
Precaução, eu tenho sempre. Não posso ser contrária àquilo que eu falo aqui dentro, a questão do uso de preservativo, a questão do uso de materiais perfurocortantes, a questão de salão de beleza, de levar material pessoal e a orientação à família. (E 0288-Assistente Social)

Tais repercussões estendem o agir dos profissionais enquanto educadores em saúde no âmbito do HIVAids à outros sujeitos e mantém para além da unidade de saúde a configuração da educação em saúde como ato-tarefa de orientar-informar para a precaução-prevenção.

\section{As condições sine qua non: educação no trabalho e estru- tura da Unidade}

Destacou-se na Rede Associativa a relação entre educação em saúde e educação no trabalho, representada pelas FR treinamento, capacit, atualiz, guias, curso. Apesar da experiência, os profissionais confirmam que têm dúvidas:

[...] mas a unidade não informou e não capacitou; falta capacitar, informar, treinar, atualidades. Recebemos atualmente treinamentos de hepatite, mas também se eu não fosse não era obrigada e tem que ser porque como vou orientar, fazer educação_saúde? (E 0273-Psicólogo)

Levei um tempo para entregar um resultado positivo, levei um tempo para dar as palestras, fazer educação_saúde [...] nós sempre estamos precisando se capacitar, tem vez que nós temos dúvida, mesmo com o tempo que nós temos aqui. (E 0274-Assistente Social)

Os profissionais referem que é importante a educação no trabalho e quando não ocorre, vão buscar informações por conta própria, como ilustram as expressões contidas em diferentes UCE: "foi fundamental o que me foi passado", "foi importantíssima a capacitação", "mas atualmente nos viramos nos trinta para ter informação atualizada", "às vezes vou para a internet", "tudo de novo que informamos é com base no que lemos". Assinalam condições e requisitos para o agir educativo. Ressaltam como condição o espaço adequado e a sua ausência é uma das justificativas apontada pelos profissionais para a não realização do agir educativo.

A questão de ideal, precisamos de um espaço melhor, mais adequado. (E 0274-Assistente Social)

É como eu te falei, estão adequadas entre aspas, mas deveria ser um espaço melhor. Mas, nem tudo é possível. ( $E$ 0287-Assistente Social)

Queríamos ter mais espaço para trabalhar com eles, fazer um trabalho_grupo de adesão, fazer reunião, umas programações, umas coisas recreativas, já pensamos nisso. ( $E$ 0265-Enfermeira) 
Nós precisamos de um espaço para orientação, nós não fazemos a palestra. O individual são só aqueles esclarecimentos que a pessoa precisaria para completar o que estava vendo no coletivo, não temos esse coletivo porque nós não temos esse espaço, nós precisamos de um local para o coletivo. (E 0288-Assistente Social)

Essas condições tanto viabilizam como inviabilizam o agir educativo, bem como justificam a presença elou a ausência da educação em saúde na unidade, e ainda podem impedir a diversificação de estratégias, que acabam ficando no plano do ideal. A educação em saúde está, com base nessas associações e discursos, delineada como um processo pedagógico, o que é analisado nas categorias seguintes.

\section{Processo Pedagógico I: conteúdos e contextos}

A Rede Associativa apontou conteúdos relacionados às práticas de educação em saúde, representados pelas FR tratamento, antirretrovira, exame. Outros conteúdos remetem ao cuidado com a saúde do outro e em casa.

Quanto aos pacientes HIV_positivo, acho necessário para orientá-los adequadamente, falar o básico do tratamento. (E 0275-Enfermeira)

Porque nós orientamos a pessoa HIV positivo aqui com relação ao tratamento, eles têm dúvidas sobre os antirretrovirais. Ele faz o exame, dá negativo, nós orientamos com relação ao risco, educação_saúde sobre o cuidado_saúde que tem que ter. (E 0274- Assistente Social)

A questão mesmo é orientar, dizer: tais objetos guardar trancados, se você tem crianças em casa, cuidado_saúde para não pisar em brinquedos, escorregar, cair, se cortar. ( $E$ 0272-Nutricionista)

Orientações para a vida cotidiana, com relação ao uso do preservativo, cuidado_saúde com o outro, cuidado_saúde em casa, com barbeador, alicate de unha, para trazer seus filhos para fazer o teste_HIV. (E 0280-Psicólogo)

Com base nas associações e discursos, pode-se inferir que a orientação-informação prestada pelos profissionais de saúde é guiada por conteúdos clínico-terapêuticos com vistas a precaução-prevenção, pois estão inseridas em contextos específicos (unidades de referência para pessoas soropostivivas para HIV), que geram práticas educativas também específicas, o que a subcategoria a seguir evidencia.

Para os profissionais, o agir educativo se concretiza nas práticas educativas realizadas em atendimentos pré e pós testagem e no aconselhamento. Percebem, no entanto, que nem sempre esse agir educativo associado ao atendimento pré e pós testagem é favorável, e reconhecem que é muita informação a ser dada à pessoa vivendo com HIV. Nesse sentido, a educação em saúde, de ocasional, poderia vir a ser permanente e obrigatória. Reconhecem, no entanto, que o agir educativo não é o único tipo de atendimento a ser oferecido nas unidades, pois estas precisam atender de forma satisfatória e integral.

Segundo minha memória, é a mesma coisa, o cuidado é o aconselhamento mesmo, e é no pós_teste_HIV, no caso se houver pessoa vivendo com HIV, a orientação é o encaminhamento. (E 0274- Assistente Social)

Atualmente é atribuído à equipe_saúde o cuidado_saúde; eu acho que é o que nós fazemos aqui no aconselhamento. (E 0280-Psicólogo)

Os percebo mais preocupados com o resultado dos exames do que com as orientações, educação saúde que faço imediatamente, pois ficam nitidamente distraídos. ( $E$ 0205-Enfermeira)

Eu vejo que muitas vezes o atendimento é segmentado, fica com orientações segmentadas, e às vezes a pessoa HIV positivo pode não ver um sentido, não ver uma articulação, são muitas informações e às vezes ele se perde. Para mim não seria compulsivo não, seria obrigatório que passasse por um período de educação_saúde. ( $E$ 0262-Nutricionista)

Segundo os profissionais de saúde, fora da unidade (contexto interno), a educação em saúde pode se concretizar em campanhas, empresas e escolas, ONG (contextos externos), com destaque para a atividade-palestra. Destacam, no entanto que as campanhas "de precaução", nem sempre atendem, são feitas de forma pontual, podem conter informações incorretas, devem ser sobre vários assuntos e é preciso utilizar diferentes canais de difusão; os profissionais acreditam nas campanhas para orientação-informação, mas no contexto HIVAids destacam que não são suficientes.

Deveria ter mais campanhas de tudo, de testagem, precaução. Porque só faz quando é dia mundial, sábado vão fazer. (E 0270-Fisioterapeuta)

Para enfrentar a Aids, não sei não, fazemos as campanhas de precaução, educação_saúde, junta com a equipe_saúde daqui, dali, mas as campanhas de precaução para mim não estão dando muito certo, porque se não, não tinha tanta gente infectada. (E 0264-Enfermeira)

Nas campanhas de televisão, algumas são até errôneas, eu acho. Nunca mais eu vi nenhuma muito boa. Mas eu acho que precisa, não pode parar. (E 0272-Nutricionista)

Nas empresas, nas escolas, em cada conjunto de quarenta pessoas que você informa bem, tira dúvida, eles são multiplicadores. (E 0273-Psicólogo)

Eu acredito que se tivessem mais políticas na atenção_básica, posto de saúde, psf, onde estão as pessoas mais diretamente envolvidas na comunidade, teríamos um 
resultado melhor, no sentido de mais palestras, dar_informação, educação_saúde. (E 1114-Médico)

Desta forma, os discursos indicam a necessidade de um agir educativo permanente e ampliado em diversificados contextos e conteúdos. Os profissionais reconhecem que é muita informação para ser trabalhada com as pessoas vivendo com HIV/ Aids, o que reforça a ideia de se ter abordagens também diversificadas e plurais, o que é discutido na subcategoria seguinte.

\section{Processo Pedagógico II: abordagens, responsabilidades e sujeitos sociais implicados}

Os profissionais apontam que no agir educativo o sentido da ação é o cumprimento das práticas prescritas e também a construção de vínculos com a pessoa vivendo com HIV/ Aids. O sentido da orientação-informação é mais amplo no âmbito individual, e reduzido no coletivo, o que se revela nas expressões contidas em diferentes UCE: "damos orientações", "damos máscara", "damos a notícia para ele", "damos o preservativo para ele", mas "pouco fazemos orientações em grupo para a adesão". Ainda sobre o agir coletivo afirmam: "antigamente nós tínhamos, acabamos deixando de fazer, se tivesse mais seria melhor, queríamos fazer um grupo, há necessidade de grupos".

Entre os discursos dos profissionais vislumbram-se indícios de um agir educativo com uma abordagem centrada no sujeito e na sua realidade. Os profissionais indicam que quando ocorre o agir educativo, que é insuficiente, está associado à adesão ao tratamento e repasse de informação:

[...] não tem preocupação de qualificar, a educação_saúde para mim é precaução como um todo e não tem, há uma necessidade de trabalho_grupo. Tem um trabalho_grupo de adesão, que se reúne uma vez por mês, mas já ouvi de uma enfermeira que entende que isso não tem nada a ver com trabalho_grupo de adesão. (E 0273-Psicólogo)

Se tivesse no trabalho_grupo de adesão, nós fazíamos, teria o dar_informação, mas é muito esporádico. (E 0275-Enfermeira)

[...] vai procurar os porquês das coisas para potencializar ou fortalecer capacidades que a pessoa soropositiva tem e que são individuais e familiares, para que resolvam as situações, não é tutelar, mas é favorecer o empoderamento daquele sujeito. (E 0230-Assistente Social)

[...] algumas orientações, educação_saúde, recomendações, são gerais, não podem faltar de um modo geral para aquelas pessoas, mas tem que ser levado em consideração o dia a dia deles, a situação deles. (E 0272-Nutricionista)

Emerge da análise que tanto há abordagens "verticalizadas" como "horizontalizadas" em desenvolvimento nas unidades. Constata-se a importância do agir coletivo (sentido positivo), com a confirmação da ausência ou insuficiência (sentido negativo). Verifica-se uma perspectiva indivíduo-centrada como coletivo-centrada, o que aponta que o agir educativo entrelaça sujeitos sociais, que estão implicados no processo, o que se revela na subcategoria a seguir.

Os profissionais atribuíram responsabilidades compartilhadas entre a equipe. Apontaram que na unidade alguns profissionais estão mais voltados para o agir educativo com as famílias. Quando assinalam os resultados do agir educativo, ressaltam que dão as orientações, mas responsabilizam os pacientes pelo fazer. Admitem que a escolaridade é um limite, e que ser ouvido e ter apoio é uma necessidade das pessoas vivendo com HIVAids. Há que se enfrentar, no entanto, outros limites, como os preconceitos. Os profissionais também mencionam outros sujeitos, que estão implicados com o agir educativo realizado nas unidades:

Passamos orientação sobre o uso de preservativo, ter cuidado saúde em casa, na higiene. Face aos familiares o serviço adota prática_de_proteção, e é a assistente social que dá a informação, que dá esse tipo de instrução, junto com o enfermeiro. (E 0246-Técnico de Enfermagem)

O resultado do trabalho eu acho que é satisfatório sim. É um prazer muito grande ver esse resultado, ver quando a pessoa faz. Porque eu sou muito franca, eu digo para eles: nós te damos parte do tratamento que são as orientações, a educação_saúde, mas quem vai fazer é você. (E 0272-Nutricionista)

A maioria dos nossos pacientes HIV_positivo tem baixa escolaridade, e deve se usar uma linguagem adequada e acessível, para que possam entender o conteúdo. (E 0217Terapeuta Ocupacional)

Os mesmos precisam ser ouvidos e precisam de apoio. (E 0275-Enfermeira)

Se nós não orientarmos esses pacientes HIV_positivo, se não esclarecermos, porque eles não têm esclarecimento nenhum, ou quando tem são informações distorcidas e preconceituosas. (E 0208-Assistente Social)

Tem que ter um treinamento, uma reunião com os familiares, orientações, educação_saúde, porque aqui nós não temos esse contato direto. (E 0277-Farmacêutico)

Nos processos pedagógicos estão implicados os educadores (a equipe de saúde) e os educandos (as pessoas vivendo com HIV/Aids e outras pessoas), e desta forma as responsabilidades podem ser compartilhadas, não só entre os educadores, mas também entre estes e os educandos. Isto indica a necessária superação da responsabilização em mão única, quando só cabe aos educandos a responsabilidade pelas ações-reações-repercussões do agir educativo, o que aponta para um processo pedagógico unilateral e não dialógico, que pode estar em curso nas unidades. O limite da escolarização pode anunciar um preconceito "implícito" entre os próprios profissionais. 


\section{DISCUSSÃO}

Com base nos conteúdos que configuram os saberes dos profissionais que atendem pessoas vivendo com HIVAids, evidenciamos que se entrecruzam dois sistemas representacionais: um sobre as práticas de cuidado às pessoas vivendo com HIM Aids e outro sobre o HIVAids, o que pode explicar o fato das representações sociais de educação em saúde aí produzidas revelarem elementos representacionais associados. Estudo afirma que a equipe de saúde que cuida dessa clientela defronta-se com aspectos específicos das pessoas vivendo com HIVAids ${ }^{(7)}$.

A representação social de educação em saúde com pessoas vivendo com HIVAids tem confluência com o cuidado, com elementos do processo pedagógico, e com a avaliação clínico-terapêutica configurando-se enquanto ato-tarefa. Se levarmos em consideração a assertiva de que a humanização no cuidado se faz presente em ações resolutivas, avaliação clínica e reconhecimento do direito da pessoa à informação, há uma associação entre educação em saúde e cuidado humanizado(8).

Constata-se nos conteúdos precaução-prevenção, consubstanciados por expressões que remetem a imagens de sangue, seringas, preservativos e materiais perfurocortantes, associados à transmissão e à auto e hetero proteção, uma ancoragem em saberes apreendidos no campo dos conhecimentos reificados associados às doenças transmissíveis (via sexual e hematológica). Em se tratando de profissionais de saúde, tal processo é convergente com sua formação e atuação, e dá sentido ao objeto.

Tais dados estão de acordo com outras pesquisas com profissionais de saúde, em que a prevenção está relacionada com práticas seguras ${ }^{(9)}$ e a educação em saúde com a transmissão de orientação-informação com vistas a que as pessoas adotem modos de vida saudáveis ${ }^{(10)}$. Os profissionais ao se referirem à educação em saúde também se lembraram das campanhas, que visam reforçar e influenciar tais modos de vida.

Verifica-se que os profissionais objetivam a educação em saúde com pessoas vivendo com HIV/Aids como orientação-informação, realizando o agir educativo por meio de diferentes conteúdos, contextos, práticas, abordagens e sujeitos.

Observa-se a presença de uma dinâmica de "tempo e movimento" que dá um sentido particular à representação social elaborada pelos profissionais. A educação em saúde revela-se em bifurcações entre um passado-forte, um presente-frágil, e um futuro-possibilidade. O tempo e o movimento entre limites e (im)possibilidades revelam-se como princípios organizadores da representação dos profissionais. Os fatores limitantes ao agir educativo em contextos HIVAids são internos-pessoais (baixa valorização da ação educativa pelos profissionais), e externos-estruturais, que se manifestam na perspectiva sócio-política (baixa capacitação e formação para educação em saúde), infraestruturais (falta espaço adequado para as ações educativas), e infra-gerenciais (falta avaliação qualitativa) ${ }^{(3)}$.

A educação no trabalho, com base nos resultados apresentados, emerge como uma das condições sine qua non para o agir educativo com as pessoas vivendo com HIVAids; os profissionais, mesmo com maior experiência, têm dúvidas e buscam informação por conta própria para suprir a ausência ou insuficiência da capacitação profissional. Esses achados remetem a estudo que reforça a necessária capacitação e atualização em especial dos profissionais com mais tempo de formados ${ }^{(11)}$.

Esta análise demonstrou a presença predominante de conteúdos clínico-terapêuticos e a condição de risco guiando o agir educativo dos profissionais. Superando a hegemonia dos conteúdos biológicos introduzidos no agir educativo nas primeiras décadas da epidemia, atualmente as premissas suscitam a consideração de aspectos subjetivos no agir educativo ${ }^{(4)}$. Apesar de se verificar uma importante mudança no modo de pensar o HIV Aids com a superação da polarização grupo de risco e população em geral, e o deslocamento do foco individual com ênfase no risco para o social com destaque para a vulnerabilidade, ainda se constata nas representações sobre Aids a responsabilização, o medo das consequências e a descrição da doença ${ }^{(12)}$.

$\mathrm{Na}$ análise apresentada emerge um conteúdo valorativo, indicando um sentido positivo e favorável à educação em saúde, que precisa ser "permanente", justificada, dentre outros aspectos, pela grande quantidade de informação necessária às pessoas vivendo com HIVAids. Os profissionais dizem que falta o agir educativo, e que nem sempre dão conta de fazê-lo. Vivenciar dimensões do HIVAAids, traz a necessidade de modelos ampliados, que deem conta de uma psico-lógica e uma sócio-lógica da epidemia, o que remete aos conteúdos representacionais em jogo nas unidades e a uma epistemo-lógica que estabeleça pontes entre o dizer e o fazer ${ }^{(13)}$.

Os resultados da análise indicaram a presença de um mosaico de perspectivas que transitam de enfoques pedagógicos verticalizados à horizontalizados, de tradicionais à críticos, anunciando uma dinâmica de transição em curso no agir educativo. A perspectiva da pedagogia crítica, que se orienta pela educação popular, vai além do repasse de informação de deveres e visa o fortalecimento da autonomia e a vivência de saúde como direito ${ }^{(4)}$. Há que se ter em conta que, para as pessoas de uma maneira geral, a representação social sobre informação consubstancia-a como a base para a construção do conhecimento $^{(14)}$ que, por sua vez, guiará as ações e modos de vida. A análise revelou que os profissionais fazem menção não só à pessoa vivendo com HIVAids, à família e à rede de contato, mas também à população de um modo geral, e referem que todos estão implicados no agir educativo.

A desinformação dá o "tom" aos discursos dos profissionais quando se referem a pessoa vivendo com HIVAids, indicando uma dimensão representacional imagética "negativa". As equipes que dialogam e se colocam numa posição também aprendente conseguem reconhecer que o "outro" não é desprovido de saber e tem potencialidades ${ }^{(15)}$. Há que atentar que o modelo cognitivo-centrado tende a falhar principalmente quando se trata de práticas em HIVAids, pois há que se lidar na orientação-informação com dimensões subjetivo-afetivas dos sujeitos sociais, que envolvem a sexualidade, as relações interpessoais e sexuais, dentre outros ${ }^{(3)}$.

\section{CONCLUSÕES}

O trabalho em saúde se dá com base em encontros (entre profissionais e entre eles e os usuários), e são fluxos-conectivos permanentes entre tais sujeitos. Tais premissas reforçam a 
ideia de educação em saúde também permanente e em rede, suscitada nos discursos dos profissionais das unidades para se chegar à integralidade nos serviços.

É preciso reforçar que os profissionais que atuam no campo da saúde desempenham um duplo papel de educador: junto à população usuária das unidades e com as equipes de saúde, e em ambos os processos educativos são mediadores e facilitadores de aprendizagens, o que conforma tanto os processos de educação em saúde como de educação no trabalho.

As representações sociais construídas pelos profissionais sobre educação em saúde com pessoas vivendo com para HIV, quando configuradas como orientação-informação para precaução-prevenção, permitem entender e mesmo explicar uma realidade que é específica, pois se dá no âmbito do cuidado "em tempos de Aids" (função de saber). As representações sociais situam os profissionais nesse campo social (as unidades de referência) enquanto cuidadores-educadores, e imprimem assim uma especificidade ao agir em saúde que é ampliado com o agir educativo aí desencadeado (função identitária); as equipes que atuam nessas unidades, por conta dessa identidade, suscitam políticas também específicas, como de educação permanente.

As representações sociais elaboradas estão guiando as práticas aí realizadas (presença) ou desejadas (idealizadas); o agir educativo nesse campo social tem uma finalidade, a precaução-prevenção, cria expectativas e dão a base para as prescrições, condutas, rotinas etc. (função de orientação). Enfim, as representações sociais dos profissionais justificam o modo de agir educativo (no passado, presente e futuro), e assim tanto poderá haver persistência de condutas como transição e até transformação das mesmas (função justificadora).

Identificar e analisar os conteúdos presentes nas representações sociais dos profissionais sobre educação em saúde à pessoa vivendo com HIV tem implicações para a educação permanente que se faz nos serviços com vistas a fortalecer o agir educativo e os processos pedagógicos. O estudo aponta subsídios para novos estudos e intervenções diversas a fim de potencializar intervenções concretas nestes contextos, com vistas a contribuir com a qualidade da prática educativa.

\section{REFERÊNCIAS}

1. Oliveira DC. Construção e transformação das representações sociais da Aids e implicações para os cuidados de enfermagem. Rev Latinoam Enferm [Internet]. 2013 [acesso em 04 de junho de 2014];21 (n. ${ }^{\circ}$ esp.):[10 telas].Disponível em: http://www.scielo.br/pdf/rlae/v21nspe/pt_34.pdf

2. Alves VS. Um modelo de educação em saúde para o Programa Saúde da Família: pela integralidade da atenção e reorientação do modelo assistencial. Interface Comun Saúde Educ [Internet]. 2005 [acesso em 04 de junho de 2014];9(16):39-52. Disponível em: http://www.scielo.br/ pdf/icse/v9n16/v9n16a04.pdf

3. Marques SC, Tyrrell MAR, Oliveira DC. As práticas educativas na prevenção do HIV/AIDS das usuárias da rede básica de saúde do Rio de Janeiro/Brasil. REME Rev Min Enferm [Internet]. 2013 [acesso em 04 de junho de 2014];17(3):538-53. Disponível em: http://www.reme. org.br/artigo/detalhes/671

4. Guedes HHS, Stephan-Souza AI. A educação em saúde como aporte estratégico nas práticas de saúde voltadas ao HIV/AIDS: o papel da equipe de saúde. Rev APS. 2009;12(4):388-97.

5. Meyer DEE, Mello DF, Valadão MM, Ayres JRCM. Você aprende. A gente ensina? Interrogando relações entre educação e saúde desde a perspectiva da vulnerabilidade. Cad Saúde Pública. 2006;22(6):1335-42.

6. Jodelet D. Representações sociais: um domínio em expansão. In: Jodelet D, organizadora. As representações sociais. Rio de Janeiro: EDUERJ; 2001.

7. Formozo GA, Oliveira DC. Representações sociais do cuidado prestado aos pacientes soropositivos ao HIV. Rev Bras Enferm. 2010;63(2):230-7.

8. Araújo FP; Ferreira MA. Representações sociais sobre humanização do cuidado: implicações éticas e morais. Rev
Bras Enferm.2011;64(2):287-93.

9. Cunha KJB, Moura MEB. Representações sociais da prevenção da infecção neonatal no olhar dos enfermeiros. Rev Interdisciplin NOVAFAPI [Internet]. 2010 [acesso em 04 de junho de 2014];3(1):34-39. Disponível em: http:// uninovafapi.edu.br/sistemas/revistainterdisciplinar/v3n1/ pesquisa/p5-v3n1.pdf

10. Gazzinelli MFC, Marques RC, Oliveira DC, Amorin MMM, Araújo EG. Representações sociais da educação em saúde pelos profissionais da equipe de saúde da família. Trab Educ Saúde. 2013;11(3):553-71.

11. Piai TH, Figueiredo RM. A co-infecção AIDS/Hepatite C e a equipe de enfermagem em um hospital especializado. Rev Eletrônica Enferm [Internet]. 2009 [acesso em 04 de junho de 2014];11(1):94-100. Disponível em: http:// www.fen.ufg.br/revista/v11/n1/v11n1a12.htm.

12. Natividade JC, Camargo BV. Representações sociais, Conhecimento científico e fontes de informação sobre Aids. Paidéia (Ribeirão Preto). 2011;21(49):165-74.

13. Andrade SA. Aconselhar, ensinar-aprender a aconselhar: interfaces de uma prática educativa em saúde [Internet]. [SI]:Departamento de DST, Aids e Hepatites Virais; [S.d] [acesso em 04 de junho de 2014]. Disponível em: http:// www.Aids.gov.br/pagina/2012/52294

14. Araujo SSS, Moura MA. Representações sociais sobre informação e conhecimento na educação a distância. Rev Encontros Bibli [Internet]. 2012 [acesso em 04 de junho de 2014];17(33):79-96. Disponível em: http://www.redalyc.org/articulo.oa?id = 14723067006

15. Fernandes MCP, Backes VMS. Educação em saúde: perspectivas de uma equipe da Estratégia Saúde da Família sob a óptica de Paulo Freire. Rev Bras Enferm. 2010;63(4):567-73. 